\title{
'Professionalism' in Second and Foreign Language Teaching: A Qualitative Research Synthesis
}

\author{
Anchalee Jansem ${ }^{1}$ \\ ${ }^{1}$ Faculty of Humanities, Srinakharinwirot University, Bangkok, Thailand \\ Correspondence: Anchalee Jansem, Faculty of Humanities, Srinakharinwirot University, Bangkok, Thailand. Tel: \\ 66-260-1770, ext. 16248. E-mail: anchalej@g.swu.ac.th
}

Received: August 15, 2017

Accepted: September 27, 2017

Online Published: December 29, 2017

doi:10.5539/ies.v11n1p141

URL: https://doi.org/10.5539/ies.v11n1p141

\begin{abstract}
This qualitative research synthesis concludes and displays pictures of professionalism in second/foreign language education. Adopting Weed's processes as the methodological framework for doing qualitative research synthesis, the researcher employed seven steps, from retrieving to selecting studies directly associated with professionalism. The findings identify the notion of professionalism in language education, external factors affecting professionalism, concerns about professionalism, and teachers as essential agents of professionalism.
\end{abstract}

Keywords: professionalism, second language, synthesis

\section{Introduction}

Due to economic and cultural change at the global level, teaching and learning a second/foreign language plays a significant role in all levels of education in every country. For example, in Europe, students in both primary and secondary schools generally learn foreign languages. Some even learn multiple languages (Devlin, 2015). In the USA, despite there not being compulsory foreign language learning for elementary schools, high schools offer a number of foreign language options, depending on the demographic contexts of each state. Thus, the implementation of second or foreign language education varies, for example, in the forms of dual language and transitional bilingual programs. Meanwhile, the term 'professionalism' has always shed light on language education. A rationale for promoting the roles of professionalism is an attempt to ensure the quality of teaching and learning a second/foreign language. This process seems to result in a number of aspects of professionalism including, for example, the concepts of ideal teachers, effective teachers, teacher education, and teacher development.

Initially, professionalism was perceived as a concept that represents meanings and qualities of ideal teachers starting with having necessary credentials (Etzioni, 1969). Similarly, teachers are expected to perform teaching tasks effectively enough to be called professionals. In the field of teacher education, therefore, teacher professionalism is regarded as missions when carrying out teacher preparation and development processes.

In other professions, in general, the concepts of professionalism have evolved depending on the movement of sociopolitical power. For example, as Evetts (2014) concluded, professionalism became evident during the early phase as a normative value, evolved through the critical phase as ideology, turned more complicated as a discourse, and has integrated diverse changes as new professionalism.

The movement and importance of professionalism also led to an increasing amount of research in different contexts. Such topics in the field of language education are no exception despite its smaller number of studies when compared to the other areas of education. The focuses include, for example, how professionalism is perceived and what counts as professionalism.

As cited in research on teacher professionalism and teacher knowledge base, Shulman's (1987) proposed that the attributes of being a professional teacher include knowledge of curriculum, content, general pedagogy, pedagogical content, education goals, educational contexts and learners. His seven categories have been cited in the literature review and expanded to integrate more characteristics required for teachers to be called professional teachers. In second language research published in the last two decades, various aims and findings have presented a wider scope of professionalism. Therefore, this study aims at identifying the synthesized findings in language education research in order to uncover the conceptualized pictures related to 
professionalism in language education.

\section{Literature Review}

Initially, the status of the teaching profession was limited to being viewed as a semi-profession, or even a craft (Flexner, 1915 cited in Bair, 2014). Later, with an attempt to elevate the status of teaching, scholars began to consider repertoires of being a full profession and the core concept of professionalism. Among the complexities of the concept of whether teaching counted as a profession were the definitions of professionalism. For example, professionalism refers to "an ideal to which individuals and occupational groups aspire in order to distinguish themselves from other workers" (Pratt \& Rury, 1991 as cited in Shon, 2006, p. 4). Note that defining 'professionalism' unavoidably relates to considering its construct. As Bair (2014)summarized from the literature in this field, the construct of professionalism is dynamic, and the assumptions are varied. Yet, the pillars of professionalism include knowledge, autonomy, and service. That is to say, without solid knowledge accompanied by particular specialization, it is unlikely for a career to be called a profession. In addition, knowledge, skills, and any other required qualities need to be accepted by a professional community. Such specialized knowledge should also benefit other communities via occupational services. In terms of different forms of professionalism, functionalist perspectives regard the shared attributes or sets of required skills, knowledge, and code of professional conduct as the elements of each occupation. However, ideological perspectives believe that self-interests of each professional community are the foundation of professionalism (Johnson, 1997 cited in Gleeson \& James, 2007).

Examining the core characteristics of professionalism in general, scholars in the field of education also attempted to explain the concept of teacher professionalism. For example, Hoyle (1980) assumes that a teacher's professionalism can be seen through the behaviors exhibited in his/her practice. Similarly, Sockett (1993) notes that there are five repertoires which form professionalism include character, commitment to change and continuous improvement, subject knowledge, pedagogical knowledge, and obligations and working relationships beyond the classroom. Later, Kramer (2003) added attitude, behavior, and communication to the list. In terms of professional requirements, Stronge (2002) asserts that the teacher should both possess and demonstrate the expertise in managing class, organizing for instruction, implementing instruction, and monitoring student progress and potential. Practically, the teacher that meets professionalism expectations recognizes the complexity of teaching, communicates clearly, and is devoted to the teaching profession through conscious services. Yet, the range of low and high professionalism tends to be too broad. Thus, M. Tichenor and J. Tichenor (2005) argue that the range is like a continuum with one end as the basic point of professionalism at which a person who teaches and receives payment and the other end as the highest standards or expectations. In addition, according to Evans (2008), professionalism can be either demanded or transformative. While demanded professionalism appears to be governed by top-down bureaucratic organizations, transformative professionalism is devised by the members of the profession themselves.

In addition to the complexity, professionalism is associated with phases viewed as the journey of its development rather than only one complete state. The first phase of professionalism is called the pre-professional age when teachers were controlled by managerial and technical work. The second phase, the autonomous professional age, provided teachers with autonomy to make decisions on curriculum development. The third phase, or the collegial professional age, highlighted the development of professional communities. The last phase, perceived as the post-professional age, becomes clear when teachers start to critically consider and question themselves what professionalism really means.

Partly due to its complexity, professionalism became a research topic and the sub- topics of studies. However, the scope is seen to be both on teacher professionalism in general and that in specific fields or subject areas in particular. Note that in the last two decades, educational research on professionalism is mainly associated with teachers' perceptions on professionalism, the changing notion of professionalism influenced by external constraints including business and political changes, and the comparison of teacher professionalism in different contexts. For example, a study in England indicated that teachers' beliefs, dedication, self-efficacy, and opinions about how the public recognize teachers affect the teachers' perception on professionalism (Swann et al., 2010). In Romania, a study revealed that advanced content knowledge, professional freedom, and the alignment with professional standards affect the formation of professionalism (Popa \& Acedo, 2006). In Australia, professionalism shares the notions of professional standards that require knowledge, practice, and engagement at the professional levels. Another study from Romania revealed that novice teachers focused on teaching skills while experienced teachers focused more on student learning. These two groups justified professionalism differently. 
In the field of second and foreign language education, and since professional teaching has become a necessary framework of the profession, an adequate number of scholarly papers on professionalism have been published. Concurrently, Faez (2011) and Leung (2012) note that language teacher education programs should take into account the concepts and movements of professionalism in order to prepare effective foreign/second/additional language teachers. Leung (2012) asserts that the first view of professionalism in language education involves the necessity of possessing professional expertise including disciplinary knowledge, knowledge of student needs, pedagogic content knowledge, and authority management. These can be called prescribed professionalism. However, with prescribed requirements of professionalism, teachers' voices seemed to be inhibited in both policy making and any documented expectations. The second view of professionalism being recognized nowadays is independent professionalism that involves individual teachers' abilities and manifests idea, teaching, and any adaptations while performing effective teaching practices. Fortunately, with the empowerment of teacher agency, teachers' voices began gradually to receive attention. This results in a wider range of research on educational professionalism in various subject areas including language education to emphasize professionalism in teachers' perspectives. Part of more vivid roles of professionalism emerged in language education when researchers began to identify the goals of second and foreign teaching and learning language. Interestingly, with similar theoretical frameworks of professionalism, different studies revealed a broad spectrum of findings ranging from teachers' perceptions to the changing concepts and the depth of professionalism. As such, a substantial amount of studies, both directly and indirectly on professionalism, have gradually contributed to research in this field. This is a reason why this study aims to synthesize research findings on professionalism to present a crystallized picture of professionalism in second and foreign language education. Two questions that guided this synthesis include: what professionalism really means, and how it is displayed in second/foreign language education.

\section{Methodology}

This study adopted Weed's (2005) meta-interpretation procedures for qualitative research with an aim to generate new interpretive findings from existing qualitative studies related to second/foreign language professionalism. Weeds commented that in addition to descriptive reviews, the synthesis of previous research can provide what researchers need via the meta-interpretation of qualitative research. In this study, an analysis of published articles in peer-reviewed journals and a set of selected studies that met the predetermined criteria were explored. The following were the inclusion criteria for selecting the studies: (a) studies that explored any aspects of professionalism in language education (b) articles that got published in peer-reviewed journals between 1995 and 2015 (c) studies that used qualitative data analysis methods, and (d) studies published in English that contain detailed findings. In retrieving qualitative studies relevant to the objectives of the study, the researcher strictly followed the criteria above, adopting purposeful sampling via electronic bibliography databases including Education Resources Information Center (ERIC) and H.W. Wilson Databases.

Adopting Weed's (2005) processes as the methodological framework for doing qualitative research synthesis, the researcher employed seven steps. Firstly, keywords were identified for accessing published articles in the electronic databases. The keywords included professionalism, professional teachers, second language teachers, foreign language, modern language, and language education. Secondly, twenty-six retrieved research articles were initially examined, with emphases on the keywords stated in the abstracts, findings, and the discussions. This stage shares Patton's (2001) explanations that purposeful sampling on the basis of the topical parameter is appropriate for qualitative research. Thirdly, the studies that did not seem to be relevant to professionalism in language education or the purposes of the synthesis were excluded. Fourthly, nine studies that met both the criteria and the relevance of the findings and the keywords were ready for the following step of a theme analysis. Fifthly, all seventeen excluded studies were re-examined in case some relevant parts were missed. At the completion of this stage, one excluded study was added to the selected list. Sixthly, the researcher identified, sorted, and grouped themes situated in each study so as to reveal the results of the research synthesis guided by the objectives. The last stage was associated with developing the findings by scrutinizing the overlapping data to yield finalized themes of professionalism in second or foreign language education. In addition, Weed (2005)'s five fundamental features were also treated as a supplementary framework. These include (a) avoiding pre-determined themes of findings, (b) focusing on the meanings on the basis of the context of each study, (c) interpreting the data that is presented in the studies, (d) limiting the theoretical sampling for the purpose of synthesis, and (e) focusing on the trustworthiness of the synthesis. In short, all seven stages together with the five features above served as the approach to conducting the present research synthesis to manipulate the answers to the guided question: What does 'professionalism' provide to language education? 


\section{Findings}

The findings in all studies contributed to this synthesis both directly and indirectly and present four key themes associated with professionalism in language education. These include the notion of professionalism in language education, external factors affecting professionalism, concerns about professionalism, and teachers as essential agents of professionalism.

\subsection{The Notion of Professionalism in Language Education}

The notions of professionalism in language teacher education cover a wide array of concepts, with detailed meanings that include both abstract and concrete features. Derived from concepts, professionalism is believed to include repertoires that, in the meantime, serve as qualities for language teachers to abide. Primarily through a basic lens, professionalism refers to the overall quality of being a subject matter specialist, educator, and human being that leads to an effective teacher (Oder, 2008). Being a subject matter specialist equipped with pedagogical competence, qualifications that meet the requirements, target language competence, and language teaching experience are the elements of professionalism. Through a lens that focuses on professionalism for educators, teamwork, classroom management, assessment, and psychological skills are all a subject matter specialist needs to exhibit while performing teaching. Additionally, another angle of professionalism involves character traits and communication competence.

Professionalism also refers to a state of effective teaching that includes an ability to integrate foreign language competence with pedagogical competence in a motivational environment for students (Oder, 2008). That is, professionalism carries the notions of high quality of teaching practices. In addition to teaching, the notion of professionalism reaches commitment to self-professional development while maintaining membership of a social context, resulting in the growth of a partnership. This notion seems to emphasize collective professionalism as a discourse of the teaching community. The additional layer of professionalism includes an ability of an individual teacher to adjust ideas, knowledge, and attitudes into any new situation. Clearly, because the emphasis on teaching, being part of a professional community, and the necessity of ongoing professional development, professionalism encompasses expectations related to all components which result in effective language teaching and leads to students' effective learning.

\subsection{External Factors Affecting Professionalism}

While the concept of professionalism has been widely integrated in all processes associated with language teacher education, professionalism itself is situated among a number of factors that have impacts on its notion. These are bureaucracy and administration, social values, and social change.

In terms of bureaucracy and administration, top-down strategies seem to intervene not only the roles but also the expectations of professionalism. With political power, administrators, mostly at the government level, can review and revise the concept of professionalism while practitioners, especially language teachers, seem to lack voices. Once professionalism has been defined and the expected qualifications issued, practitioners can never resist, or even negotiate them. As such, whenever policies change, new notions and expectations of professionalism emerge. This results in changes in the forms of, for instance, emphases and required qualifications of second language teachers. In other words, due to mere centralized bureaucracy and administration, professionalism plays a role of top-down rigid requirements.

Social values would be another influential factor for professionalism. One of these is the status of the language and the expected outcomes of teaching and learning a language. The status of the language also influences how native speakers of the target language are viewed. That is, native speakers are still believed to be more qualified than non-native teachers. Likewise, native speakers are believed to be qualified by nature because of 'nativeness' that unarguably conforms to the concept of professionalism.

The other factor, social change, became an external factor that may provide directions for defining professionalism in language education. Inevitably, with the increasing power of business and globalization, professionalism expands itself yielding more complex notions. Concurrently, business-based movements add measurable qualifications and expectancies into professionalism that share those of business contexts.

\subsection{Concerns about Professionalism}

Various notions of professionalism and factors presented above potentially trigger language teachers to raise at least three major concerns. The first one is about the concepts and attributes of professionalism demanded by agents distant from language education fields. This may cause gaps between professionalism perceived by insiders and assumed by outsiders. Incongruent perceptions would discourage language teacher educators and practitioners whose voices seen to be void. Moreover, this concern relates to the perception of devalued teachers' 
identities.

The other concern is a consequence of the superiority of native speakers to non-native teachers as perceived by administrators and stakeholders. This value not only affects misconceptions of professionalism but also challenges the concept of qualified teachers. On the basis of professional attributes, being a native speaker should not compensate for a lack of necessary qualities for professionalism.

\subsection{Teachers as Essential Agents of Professionalism}

While external factors and concerns seem to exist in the discourse of professionalism, second and foreign language teachers believe that the concept of self also exists. Yet, they seem to fail to voice their selfness individually. Self in this instance refers to few roles that teachers play in language education discourse. The first role involves attempts to articulate beliefs with strong identity to, if possible, resist external power. Moreover, teachers themselves believe that they can internally reconstruct knowledge that may bring about change in language teacher professionalism. In doing this, when limited opportunities allow, teachers engage in self-reflection as a gateway to critically analyze their social environment and their professional stories. Through self-reflection, language teachers employ a self-designated discourse of agency that, in the meantime, empowers them through professional development based on their needs. When teachers share similar missions that professionalism can be embedded with their identity, communities are formed. This can result in professional empowerment that is strong enough to contribute to educational society. For example, new meanings of curriculum and learning/teaching standards were drafted and enacted by associations of second/language teachers.

\section{Discussion}

Overall, this study demonstrates that professionalism definitely exists in the field of language education. The findings also lead to discussion. First, the notions and expected characteristics of professionalism have received much attention. A reason for this could be because of concrete lists on the basis of the concepts. These all are broadly consistent with Socket's (1993) proposed repertoires. As Socket notes, professionalism is exhibited through character, commitment to change and continuous improvement, subject knowledge, pedagogical knowledge, and obligations and working relationships beyond the classroom. This study confirms these all as well as a repertoire on professional development as added points. It should be noted that all elements of professionalism serve as criteria professional teachers are supposed to meet. Nonetheless, part of the concept of professionalism maintains its complexity because no single set can represent the complete notion. Hence, instead of solely focusing on the definite meanings, manipulating core features of professional practices and effective language teachers should be highlighted.

The concentrated findings also uncover language teachers' perspectives on their restricted voices. It is not surprising that they raised question of who really defined professional for whom. Similarly, regardless of specific concepts, professionalism somehow leaves discrepancy between practitioners and those who can affect the expectations. To confirm the vitality of professionalism in language teaching, particularly disciplinary knowledge, pedagogical skills, and dispositions, no teachers should receive privilege. If possible, it can be argued that an issue on the native-non-native dichotomy should not devalue either category. In short, professionalism is not limited to who a language teacher is, but how professionally an individual teacher performs teaching practices instead

The other aspect of the findings indicated that professionalism is dynamic. According to Sachs (2001), professionalism gradually evolves over time and contexts as a response to external power including, for example, scientific development and business movement. With this in mind, new forms and concepts of professionalism have been adapted to serve business needs. If the external power maintains its strengths, professionalism in language education would also face changes led by outsiders' needs. A significant part of this seems to be professionalism that demands accountability of all who are responsible for the success of language education. Eventually, professionalism would continue being shaped by broader stakeholders.

\section{Conclusion}

This study employed a qualitative research synthesis method with a focus on synthesizing professionalism in second/foreign language education. Drawing on the findings and data of previous research published in the last 15 years, this study has presented four themes: the notions of professionalism in language education, external factors affecting professionalism, concerns about professionalism, and teachers as essential agents of professionalism. All of the four themes seem to be interwoven and display professionalism in this field. The implications of this study include displaying synthesized pictures of professionalism when considering policies 
and practices about language teaching education, from educating pre-service teachers to managing professional development activities. More importantly, this study lays out the complexity of professionalism which can be studied in more depth.

\section{Acknowledgments}

This study was financially supported by a research grant provided by the Faculty of Humanities, Srinakharinwirot University.

\section{References}

Bair, M. (2014). Teacher Professionalism: What Educators can learn from social workers. Mid-Western Educational Researcher, 26(2), 28-57.

Devlin, K. (July 13, 2015). Learning a foreign language a 'must' in Europe, not so in America. Facttank: News in the numbers. Retrieved from http://www.pewresearch.org/fact-tank/2015/07/13/learning-a-foreignlanguage-a-must-in-europe-not-so-in-america/

Etzioni, A. (1969). The semi-professions and their organization; teachers, nurses, social workers. New York: Free Press.

Evetts, J. (2011). Professionalism as an Occupational Value: Theoretical challenges in the sociology of professions. Retrieved from http://metices.ulb.ac.be/IMG/pdf/Louvain_Workshop_Presentation.pdf

Faez, F. (2011). Points of departure: Developing the knowledge base of ESL and FSL teachers for K-12 programs in Canada. The Canadian Journal of Applied Linguistics, 14(1), 48-82.

Gleeson, D., \& James,D. (2007). The paradox of professionalism in English further education: a TLC project perspective. Educational Review, 59, 451-467. https://doi.org/10.1080/00131910701619340

Kramer, P. (2003). The ABC's of professionalism. Kappa Delta Pi Record, 40(1), 22-25. https://doi.org/10.1080/00228958.2003.10516409

Leung, C. (2012). Second/Additional Language Teacher Professionalism-What is it? Retrieved from http://www.andrasprak.su.se/polopoly_fs/1.203898.1411040092!/menu/standard/file/Constant\%20Leung.pd $\mathrm{f}$

Oder, T. (2008). The professional foreign language teacher in Estonia: Students' and principals' perceptions. Teacher Development, 18(4), 482-494. https://doi.org/10.1080/13664530802259297

Patton, M. Q. (2001). Qualitative Research and Evaluation Methods (2nd ed.). Thousand Oaks, CA: Sage Publications.

Popa, S., \& Acedo, C. (2006). Redefining Professionalism: Romanian Teachers and the Private Tutoring System. $\begin{array}{lll}\text { International Journal of Educational Development, } & \text { 26(1), }\end{array}$ https://doi.org/10.1016/j.jiedudev.2005.07.019

Sachs, J. (2001). Teacher professional identity: Competing discourses, competing outcomes. Journal of Education Policy, 16, 149-161. https://doi.org/10.1080/02680930116819

Shon, C. K. (2006). Teacher Professionalism. Faculty Publications and Presentations. Retrieved from http://digitalcommons.liberty.edu/educ_fac_pubs/46

Shulman, L. S. (1987), Knowledge and teaching: Foundations of the new reform. Harvard Educational Review, 57(1), 1-22. https://doi.org/10.17763/haer.57.1.j463w79r56455411

Sockett, H. (1993). The moral base for teacher professionalism. New York, NY: Teachers College Press.

Stronge, J. (2002). Qualities of effective teachers. Alexandria, VA: Association for Supervision and Curriculum Development.

Swann, D., McIntyre, D., Pell, T., Hargreaves, L., \& Cunningham, M. (2010). Teachers' conceptions of teacher professionalism in England in 2003 and 2006. British Educational Research Journal, 36, 549-571. https://doi.org/10.1080/01411920903018083

Tichenor, M. S., \& Tichenor, J. M. (2005). Understanding Teachers' Perspectives on Professionalism. Professional Educator, 27(1-2), 89-95.

Weed, M. (2005). Meta Interpretation: A Method for the Interpretive Synthesis of Qualitative Research. Retrieved from http://www.qualitative- research.net/index.php/fqs/article/view/508/1096 


\section{Copyrights}

Copyright for this article is retained by the author(s), with first publication rights granted to the journal.

This is an open-access article distributed under the terms and conditions of the Creative Commons Attribution license (http://creativecommons.org/licenses/by/4.0/). 